\title{
Milliliter per Day per Meter Squared
}

National Cancer Institute

\section{Source}

National Cancer Institute. Milliliter per Day per Meter Squared. NCI Thesaurus. Code C120773.

A unit of concentration equal to milliliter per day divided by meter squared. 